\title{
Do planejamento a prática docente: relato de implantação do Programa Mais Educação em uma cidade do oeste Catarinense
}

\author{
From planning to teaching practice: report on implementation of the More \\ Education Program in a west catharian city
}

De la planificación a la práctica del profesor: informe sobre la aplicación del Programa Más Educación en una ciudad del oeste de Santa Catarina

Marineiva Campos de Oliveira

Unoesc.

marineiva.oliveira@unoesc.edu.br

Anderson Luiz Tedesco

Unochapecó

anderson.tedesco@unochapeco.edu.br

Elcio Cecchetti

Unochapecó

elcio.educ@hotmail.com

\begin{abstract}
Resumo: O objetivo desta reflexão é apresentar o processo de implantação do Programa Mais Educação em um município do Oeste Catarinense. No decorrer do relato, descreve-se a importância do planejamento das práticas dos educadores do Programa Mais Educação, com foco na participação coletiva e na formação continuada. Nesse intuito, para uma contribuição relevante, foram entrevistados três monitores do Programa Mais Educação e dois professores da escola que atendem os alunos do Ensino Fundamental da escola da Rede Municipal, localizada do Oeste Catarinense. Os resultados mostram que os professores entrevistados relacionam a formação continuada com o planejamento coletivo na atuação escolar, considerando-a de fundamental importância para a construção de suas práticas. Conclui-se que; será possível constatar que boas práticas docentes só são realizadas se planejadas, e melhoradas se forem planejadas no coletivo, e que é necessária formação continuada focada na Educação Integral para que atenda aos anseios dos professores.
\end{abstract}

Palavras-chave: Formação Continuada. Planejamento. Práticas. Programa Mais Educação.

Abstract: The objective of this reflection is to present the process of implementation of the More Education Program in a municipality of Western Santa Catarina. In the course of the report, the importance of planning the practices of the More Education Program educators is described, focusing on collective participation and continuing education. For this purpose, for a relevant contribution, three monitors of the Mais Educação Program and two school teachers who attend the elementary school students of the Municipal Network school, located in the Western Santa Catarina, were interviewed. The results show that the teachers interviewed relate continuing education with collective planning in school performance, considering it of fundamental importance for the construction of their practices. Finally, it will be noted that good teaching practices are only realized if planned, and improved if they are planned in the collective, and that continuing education focused on Integral Education is necessary to meet the wishes of teachers. 
OLIVEIRA, Marineiva Campos de; TEDESCO, Anderson Luiz; CECCHETTTI, Elcio. Do planejamento a prática docente: relato de implantação do Programa Mais Educação em uma cidade do Oeste catarinense

Key-words: Continuing Formation. Planning. Practices More Education Program.

Resumen: El propósito de esta reflexión es presentar el proceso de implementación del Programa Más Educación en un municipio del Oeste de Santa Catarina. En el informe, se describe la importancia de planificar las prácticas de los educadores del Programa Más Educación centrándose en la participación colectiva y la educación continua. Para este propósito y para una contribución relevante, se entrevistó a tres monitores del Programa Más Educación y dos profesores de la escuela que acompañan a los estudiantes de la escuela primaria del municipio, del Oeste de Santa Catarina. Los resultados muestran que los profesores entrevistados relacionan la educación continua con la planificación colectiva en el desempeño escolar, considerándola de fundamental importancia para la construcción de sus prácticas. Finalmente, se observará que las buenas prácticas de enseñanza solamente si realizarán y serán mejoradas si los profesores las practicaren en el colectivo, y que la educación continua centrada en la Educación Integral es necesaria para satisfacer los deseos de los profesores.

Palabras clave: Formación continua. Planificación. Prácticas. Programa Más Educación.

\section{Introdução}

Este trabalho objetivou apresentar reflexões sobre o processo de implantação do Programa Mais Educação em um município do Oeste Catarinense, em específico sobre o objeto de estudo deste trabalho; o planejamento das práticas de ensino no Programa. A análise, com fundamentos na perspectiva histórico-cultural, nos possibilita compreender o planejamento de práticas de ensino como um processo que deve se constituir como objeto de estudo na formação continuada, entendendo essa formação como um espaço dialógico em que se centram esforços para elaborações de condições para a aquisição, apropriação, incorporação e assimilação de conceitos científicos que superem os abstratos no processo escolar de formação humana. Para atender essas premissas, em uma organização dialógica de formação e planejamento docente, deve-se possibilitar e situar o professor como autor do planejamento de suas práticas. Contudo, o que se observa é que muitas vezes as formações que chegam à escola trazem consigo, de modo pronto e acabado, o quê e de que forma se deve ensinar.

Assim, legitimamos a importância do diálogo de/em coletivamente dos professores na organização de formações continuadas e de planejamento de ensino, principalmente para a Educação Integral, pois entende-se que a Escola em tempo integral é o espaço potencializador de integração curricular e de um projeto educativo dialógico e transformador, que possibilita um redimensionamento do conhecimento que, assentado em uma compreensão emancipadora de Educação, possa contribuir para o redesenho dos planejamentos de ensino. 
OLIVEIRA, Marineiva Campos de; TEDESCO, Anderson Luiz; CECCHETTI, Elcio. Do planejamento a prática docente: relato de implantação do Programa Mais Educação em uma cidade do Oeste catarinense

No cenário analisado, o professor quem prepara as condições de aprendizagem e deve problematizar a realidade, a fim de que os estudantes busquem soluções, o que leva ao desenvolvimento de diversas competências e habilidades, cujo sucesso depende do planejamento das aulas por parte do professor. Por isso, refletir sobre os relatos dos sujeitos envolvidos com o Programa Mais Educação nos possibilita compreender a problemática que nos conduziu a análise; que concepção, fundamentos e organização do planejamento de ensino o Programa potencializa?

Para isso, foram entrevistados três monitores do Programa e dois professores da escola. Caracterizamos a pesquisa como de campo a qual atendeu aos rigor científico e sigilo aos dados dos sujeitos participantes. E, para atender ao objetivo proposto, na seção seguinte, discute-se sobre o Programa Mais Educação, o primeiro contato com o programa; as relações dos educadores do programa na construção do planejamento de suas práticas; as formações continuadas que contribuam com as práticas dos professores do Programa Mais Educação. Na sequência, apresentamos os procedimentos metodológicos utilizada para a realização da pesquisa; seguida da apresentação e análise dos resultados, etapa em que se discutem os resultados e com base neles se chegou as considerações finais.

\section{Adesão ao Programa Mais Educação na escola}

O Governo Federal brasileiro na busca por ofertar uma escola pública que desenvolva seu trabalho na perspectiva de Educação Integral, cria o Programa Mais Educação que abrange todo território brasileiro. Este Programa é uma ação que busca oferecer aos alunos de escola pública uma educação integral, ampliando o tempo da jornada escolar com a realização de atividades socioeducativas em turno oposto da sua participação no currículo obrigatório (BRASIL, 2007).

O município participante da pesquisa aderiu em apenas uma escola, de periferia, o Programa Mais Educação no ano de 2011. Buscava-se com esse programa proporcionar aos alunos uma educação que contemplasse o seu desenvolvimento pleno considerando o aspecto afetivo, intelectual, moral e social que constitui o ser como um todo.

Desse modo, as oficinas escolhidas foram de Recreação e Lazer, Cine Clube, Banda Fanfarra, Matemática, Letramento e Horta, a escolha dessas deu-se por acreditar que essas pudessem colaborar efetivamente para o desenvolvimento pleno e integral do indivíduo, propiciando uma aprendizagem significativa que verdadeiramente prepare o indivíduo para a vida social. 
OLIVEIRA, Marineiva Campos de; TEDESCO, Anderson Luiz; CECCHETTTI, Elcio. Do planejamento a prática docente: relato de implantação do Programa Mais Educação em uma cidade do Oeste catarinense

Ao escolher as oficinas, a preocupação dirigiu-se quando ao espaço físico para que essas pudessem ser realizadas, assim, firmou-se uma parceria com o Centro de Atendimento à Criança e ao Adolescente (CEACA), esse local foi utilizado para a realização da oficina de Cine Club e para os almoços, as demais oficinas foram realizadas na própria escola.

A parceria com o CEACA estabelecida pensou-se então na contratação de monitores, levanta-se a problemática de quem poderia assumir as oficinas. A escolha deu-se por contratar estagiários que atuavam no CEACA, assim, contrataram-se doze (12) estagiários de diferentes áreas. Para o almoço foi possível contar com as cozinheiras do CEACA e algumas da escola, para a oficina da horta foi contratado um senhor da comunidade, esse era presidente da Associação de Pais e Professores (APP), nessa oficina a professora da disciplina de Ciências da escola auxiliou. Para as demais, contratou-se dois (2) monitores por oficina, esses monitores cursavam o Ensino Médio, salvo em dois casos que cursavam psicologia e Educação Ambiental.

Ao iniciar o Programa, depara-se com a necessidade do planejamento que segundo Vasconcellos (2000, p. 79) “[...] planejar é antecipar mentalmente uma ação ou um conjunto de ações a ser realizadas e agir de acordo com o previsto. Planejar não é, pois, apenas algo que se faz antes de agir, mas é também agir em função daquilo que se pensa.".

Em conformidade com as escritas de Vasconcellos, entende-se que planejar é antecipar ações, mas, que para isso, antes é necessário conhecer sobre o que se vai planejar, e, nesse sentido, surge a necessidade de expor os objetivos do Programa de forma esclarecedora evitando possíveis dúvidas sobre o que é o Mais Educação, assim seria o primeiro passo para a construção do planejamento.

Nesse sentido, organizou-se um momento de apresentação do Programa Mais Educação à comunidade, a todos da unidade escolar incluído os estagiários do Programa. Após, organizouse um momento de planejamento, no qual alguns, poucos, professores da escola se dispuseram em auxiliar na construção do planejamento. A dificuldade encontrada foi que os professores conduziam a construção do planejamento de maneira igual a do currículo obrigatório escolar. Segundo Moll (2004) afirma que o planejamento deve ser diferenciado, não se trata de esvaziamento de conhecimento, trata, pois, de uma necessidade de estruturar um planejamento coerente com a proposta do Programa Mais Educação, que de acordo com a autora: 
OLIVEIRA, Marineiva Campos de; TEDESCO, Anderson Luiz; CECCHETTI, Elcio. Do planejamento a prática docente: relato de implantação do Programa Mais Educação em uma cidade do Oeste catarinense

É uma estratégia para atingir a Educação Integral vista como o modelo ideal para possibilitar o desenvolvimento integral do indivíduo, de maneira a preparálo para vida por meio de práticas educacionais significativas. Surgiu em 2007, através da iniciativa do Governo Federal, tal política traz o ideal de desenvolver, em todo território brasileiro, uma Educação Integral. (MOLL, 2004, p. 410).

No entanto, para a concretização de um ideal desse porte, muito ainda havia de se fazer, principalmente na questão de que o Programa fosse aceito por todos, pois, além de auxiliar na aprendizagem do aluno, possibilita melhoras em seu comportamento pois, com a participação nas oficinas esse interage e conhece ambientes diferentes do ambiente em geral tradicional de sala de aula.

É na relação com o outro que as unidades podem ser contempladas, nessa premissa, evidencia a importância da coletividade:

Ação genuinamente humana, aquela que merece esse nome, é sempre reflexiva,
ou seja, possui efeitos duradouros na pessoa que a realiza, e não somente no
meio que se desenvolve. Somos feitos por aquilo que fazemos, pelo modo
como agimos, então, um efeito desse reflexo da ação (reflexão é o processo ou
o resultado de refletir e de reflexionar) é a geração da consciência sobre a ação,
que é manifestada na forma de representações, de lembranças ou de esquemas
cognitivos e crenças que podem ser comunicadas, nutrindo a memória do
material para pensar sobre as ações passadas e presentes e para orientar outras
futuras. (SACRISTÁN, 1999, p. 99).

Pensar em ações passadas e presentes como norte de ações futuras é um ato de coletividade, o qual busca-se com o Programa Mais Educação. Essa coletividade pode ser entendida como uma estratégia de estabelecer uma relação entre professores e monitores para que ocorra a construção de um planejamento coletivo que é "Um processo de racionalização, organização e coordenação da ação docente, articulando a atividade escolar e a problemática do contexto social" (LIBÂNEO, 1994, p. 222).

No coletivo é que ocorre a integração e a interação com vista à obtenção de resultados positivos no processo de ensino e aprendizagem do aluno, pois, trocas de conhecimentos podem ser estabelecidas melhorando e adaptando o planejamento. Salienta-se que a busca pela coletividade e a interação entre professores e monitores, dar-se-á pela necessidade de que as práticas dos monitores atendam a demanda das oficinas e de certo modo que sejam diferenciadas do currículo formal da escola.

Ao adentrar-se nesse debate, evidencia-se a real necessidade de que haja um processo de formação continuada com a temática de Educação Integral, mas que essa seja pensada de acordo com os estudos de Mizukami (2002) a qual destaca que deve-se pensar principalmente que 
OLIVEIRA, Marineiva Campos de; TEDESCO, Anderson Luiz; CECCHETTTI, Elcio. Do planejamento a prática docente: relato de implantação do Programa Mais Educação em uma cidade do Oeste catarinense

aprender a ensinar e a se tornar professore são processos contínuos e não eventos voltados à resolução de problemas imediatos, ou seja, não pode ser uma breve apresentação dos objetivos mas uma longa discussão e alteração desses.

Acredita-se que com formações continuadas com a temática, os professores da escola e os monitores poderiam estar em comunhão de ideias para a construção de planejamentos que auxiliem na melhora do processo de ensino-aprendizagem de nossos alunos.

\section{Procedimentos metodológicos: percursos estruturais e reflexivos}

Com base nos procedimentos técnicos adotados em relação às fontes de informação e procedimentos de coleta de dados, o estudo em questão é caracterizado como pesquisa de campo e foi realizado na escola da rede municipal do Oeste de Santa Catarina. SC, com três (3) monitores do Programa Mais Educação e dois (2) professores da escola, organizados no quadro 1. Destaca-se que para realização da pesquisa de campo se seguiram todas as orientações e diretrizes éticas na escolha dos sujeitos de pesquisa e no tratamento com os dados. Conforme orientações de Bicudo (2006, p. 22) “requer, no entanto, planejamento prévio e manutenção do componente ético, desde a escolha do participante, do entrevistador, do local, do modo ou mesmo do momento para sua realização" (BICUDO, 2006). Por tratar-se de um estudo avaliativo, com características pedagógicas, não existe uma obrigatoriedade em submeter ao Comitê de Ética em Pesquisa. Assim como consta na própria Resolução 466 de 2012, em seu inciso "II.10 - participante da pesquisa - indivíduo que, de forma esclarecida e voluntária, ou sob o esclarecimento e autorização de seu(s) responsável(eis) legal(is), aceita ser pesquisado", pois trata-se exclusivamente de uma avaliação do Programa Mais Educação, não terá implicações psicológicas ou testes em laboratórios com os sujeitos pesquisados.

Quadro 1 - Sujeitos da pesquisa e suas respectivas funções no Programa Mais Educação

\begin{tabular}{|l|l|}
\hline \multicolumn{2}{|c|}{ SUJEITOS DE PESQUISA } \\
\hline Monitor 1 & Professor 1 \\
\hline Monitor 2 & Professor 2 \\
\hline Monitor 3 & \\
\hline
\end{tabular} Fonte: Dados da pesquisa elaborados pelos autores em 2019.


OLIVEIRA, Marineiva Campos de; TEDESCO, Anderson Luiz; CECCHETTI, Elcio. Do planejamento a prática docente: relato de implantação do Programa Mais Educação em uma cidade do Oeste catarinense

Para a coleta de dados, utilizamos um questionário semiestruturado, com perguntas abertas e objetivas sobre o Programa Mais Educação, a formação, a coletividade no planejamento de suas práticas e formação continuada.

Tendo em vista os procedimentos técnicos, trata-se de uma pesquisa descritiva, em função de ser um relato de experiências de uma determinada população, especificamente, a visão de monitores e professores do Programa Mais Educação acerca do planejamento de suas práticas e a formação continuada. Gil (2002) explica que esse tipo de pesquisa observa, registra, analisa e correlaciona fatos ou fenômenos (variáveis) sem manipulá-los.

Do ponto de vista metodológico, a pesquisa será de natureza qualitativa e se fundamentará na revisão bibliográfica. Sabe-se que o aspecto qualitativo de uma pesquisa orienta todos os passos da interpretação e análise dos conceitos filosóficos e das relações que se estabelecem com o fenômeno humano. Também entendemos que a pesquisa qualitativa na área da educação, consiste em "[...] um conjunto de práticas materiais e interpretativas que dão visibilidade ao mundo. Essas práticas transformam o mundo em uma série de representações [...]” (DENZIN; LINCOLN, 2006, p.17). Nesse nível, a pesquisa qualitativa envolve uma abordagem interpretativa, o que significa que seus pesquisadores estudam as coisas em seus cenários socioculturais, tentando entender, ou interpretar, os fenômenos em termos de significados que as pessoas e eles conferem.

Entendemos, por isso, que no campo da educação, com seus múltiplos fenômenos, a pesquisa de natureza qualitativa tem maiores condições de auxiliar na produção de conhecimentos pertinentes, que auxiliem na compreensão dos processos formativos e na proposição de novos modos do fazer pedagógico. A revisão bibliográfica ou de literatura, consiste numa revisão "desenvolvida a partir de material já elaborado, constituído principalmente de livros e artigos científicos" (GIL, 2002, p. 50). Em nossa pesquisa, essa revisão centrar-se-á em obras (artigos, livros e coletâneas) dos principais autores e especialistas no tema abordado, alguns já mencionados anteriormente.

Desse modo, a análise dos dados/conceitos também seguirá a perspectiva da hermenêutica filosófica, com esforço para contextualizar, compreender e aplicar os principais conceitos e categorias advindos da pesquisa. Nosso intento se constitui nesse exercício conceitual, mediante contextualização, compreensão e aplicação, possibilite-nos elencar elementos que nos auxiliem numa melhor compreensão do fenômeno educacional atual e nos 
OLIVEIRA, Marineiva Campos de; TEDESCO, Anderson Luiz; CECCHETTTI, Elcio. Do planejamento a prática docente: relato de implantação do Programa Mais Educação em uma cidade do Oeste catarinense

habilite, enquanto pesquisadores e educadores, a melhorar a qualidade de nossas ações educacionais, ou seja, os processos formativos e colaborativos.

\section{Resultados e análise da construção do planejamento do Programa Mais Educação}

No primeiro dia, segunda-feira do mês de outubro de 2001, inicia-se o Programa Mais Educação na Escola, neste dia, após a apresentação breve dos objetivos do Programa para a comunidade e todos da escola, nos reunimos em uma sala junto com a direção da escola, os monitores, e dois professores, o anseio começa logo no primeiro dia, os professores que deveriam estar presentes para o debate e a construção do primeiro planejamento não ficaram.

Continuamos $^{i}$ na reunião, lembro que pegamos alguns livros com títulos relacionados com as oficinas, os dois professores que ficaram, uma de Ciência e um de Geografia, nos auxiliaram no planejamento de todas as oficinas, esse planejamento foi elaborado para uma semana, assim, seria um teste até que os livros didáticos que a escola havia comprado exclusivos para os monitores chegassem.

Os monitores nesse momento só ouviram e escreveram no caderno, afinal não tinham a experiência de estar sozinho como gerentes de classe. Após as escritas, as leituras e os debates, os monitores começaram a indagar sobre como poderiam aplicar aquelas atividades, os professores auxiliaram e muito nesse momento, sanando as dúvidas e principalmente incentivando aos monitores construírem sua autonomia.

$\mathrm{Na}$ terça-feira, momento de receber as crianças, aproximadamente 30 crianças por oficina, dividas em dois turnos eram 15 por monitores, passei o tempo todo nas salas para possível auxílio, finalizamos o dia. Marcamos para nos encontrarmos 30 minutos antes do início no dia seguinte, assim foi feito.

Quarta-feira, 30 minutos antes, todos estavam na escola, conversamos como foi o primeiro dia, empolgados os monitores respondem que gostaram, mas que perceberam que algumas coisas deveriam ser ajustadas para o próximo planejamento. Terminado o tempo para conversa, inicia o turno novamente.

Os dias se passaram e finalmente chega a sexta-feira, dia de planejamento, nos reunimos novamente na escola logo no fim da tarde, solicitamos que os professores da escola permanecessem para nos auxiliar, conseguimos a presença de cinco, os mesmos dois e agora um

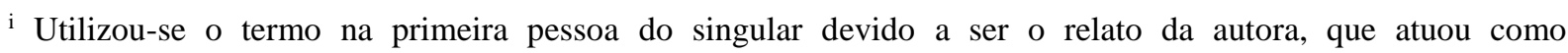
coordenadora do Programa Mais Educação da escola que é o campus da pesquisa.
} 
OLIVEIRA, Marineiva Campos de; TEDESCO, Anderson Luiz; CECCHETTI, Elcio. Do planejamento a prática docente: relato de implantação do Programa Mais Educação em uma cidade do Oeste catarinense

de matemática, um de Musical e outro de Língua Portuguesa. Iniciemos a conversa sobre os anseios, as dificuldades e as felicidades da semana, muitos relatos positivos e alguns de dificuldades.

Os professores se reuniram cada um com a dupla de monitores que atuavam na oficina relacionada com as suas áreas, os monitores de oficinas das quais nenhum professor da área compareceu foram orientados pela direção e coordenação. Os materiais didáticos já haviam chego, assim, os professores conseguiram construir uma outra visão de planejamento, pois, até o momento pensavam que as oficinas funcionariam como um reforço pedagógico, o que passa longe de ser.

Com a participação de alguns professores inicia-se o momento de planejamento coletivo, no qual professores e monitores constroem junto a proposta de atividades, o mais interessante é que tudo teve início após os relatos de dificuldades, assim, tudo foi feito para que essas fossem evitadas. Conclui-se então o planejamento para mais uma semana.

No decorrer dos dias, dos meses, sempre solicitamos a participação de mais professores, mas o que conseguimos foram os mesmos cinco que "abraçaram o Programa” e contribuíram e muito com seus conhecimentos e principalmente experiências.

Inicia-se o relato dos monitores sobre suas experiências acadêmicas, eles descrevem que cursam o Ensino Médio, finalizam no ano corrente, 2011, e que mesmo atuando como estagiários na área do magistério não têm conhecimento do que é um planejamento, que sentem dificuldades em planejar suas práticas e salientam a importância de auxiliadores, professores da escola no momento dessa construção. Segundo Oliveira (2011) destaca que o planejamento é um instrumento didático-pedagógico necessário à execução da atividade docente no cotidiano escolar colocando-o como elemento básico, conceito que abre um debate sobre a importância da organização coletiva das atividades profissionais de todos os envolvidos e comprometidos com a qualidade e tempo despendido à construção dos saberes no âmbito escolar. Por isso,

O planejamento escolar é uma tarefa docente que inclui tanto a previsão das atividades em termos de organização e coordenação em face dos objetivos propostos, quanto a sua revisão e adequação no decorrer do processo de ensino. O planejamento é um meio para programar as ações docentes, mas é também um momento de pesquisa e reflexão intimamente ligado à avaliação. (LIBÂNEO, 1994, p. 34).

Constata-se que o planejamento é um processo racional, organizacional e com intensa ação docente, um fato que articula toda a atividade escolar em seu contexto social, e que deve ser 
OLIVEIRA, Marineiva Campos de; TEDESCO, Anderson Luiz; CECCHETTTI, Elcio. Do planejamento a prática docente: relato de implantação do Programa Mais Educação em uma cidade do Oeste catarinense

construído de forma coletiva, com a participação democrática e construtiva de quem já detêm de certas experiências. Os monitores continuam e relatam que:

[...] trocas de saberes possibilitam a construção de novos saberes que com a teoria se transformam em conhecimentos, mas não somos bem aceitos pelos professores da escola, nós não, o Programa, parece que eles nunca tem tempo de participar de nossos planejamento.[...] (Monitor 1 e 2).ii

Destaca-se que os monitores sentem dificuldades na questão de planejamento e relacionamento com os professores, pois, precisam de auxilio e poucos se submetem a ajudar.

Para Vasconcellos (2000), o planejamento deve ser coletivo de forma que todos possam compreende-lo como um instrumento capaz de intervir em uma situação real para transformá-la, portanto, para transformar a realidade é preciso conhecer e partilhar desses saberes. E, além disso, há necessidade de uma mediação teórico-metodológica de forma colaborativa para a ação consciente e intencional de todos os sujeitos envolvidos no processo escolar, pois somente o envolvimento de todos possibilita e potencializa o processo de ensino e aprendizagem. Necessidade atendida no contexto desta pesquisa, pois, os sujeitos consideram que,

[...] quando começamos dois professores nos auxiliavam no planejamento, claro que tínhamos o auxílio da coordenadora, mas percebemos uma enorme diferença, e positiva, no momento em que os outros, poucos, foram chegando, conseguíamos conversar e debater assuntos de aulas, de como dar aula, dos motivos das atividades e como essas auxiliam na concretização dos objetivos do Programa[...] (Monitor 3) ${ }^{\text {iii }}$

Com base nesses relatos, é possível perceber que a coletividade na construção de um planejamento pode mudar o rumo de muitas práticas, beneficiando e ampliando o conhecimento de nossos alunos.

Para Vasconcellos (2000) o planejamento coletivo relaciona-se a contribuição dos professores uns com o outro discutindo articulando e debatendo suas dificuldades e superações por meio das reflexões de suas práticas, reflexão que potencializa melhoras a cada momento de ação educacional.

O relato dos professores é entorno de formação inicial e continuada relacionada com a Educação Integral e o Programa Mais Educação, um professor participa dos planejamentos coletivos e outro, muitas vezes convidado, ainda não participa. Para Vasconcellos (2000, p.43), “planejar é elaborar o plano de intervenção na realidade, aliando às exigências de intencionalidade

\footnotetext{
ii Monitor 1 oficina de Letramento, Monitor 2 oficina de matemática.

iii Monitor 3, oficina de Cine Clube
} 
OLIVEIRA, Marineiva Campos de; TEDESCO, Anderson Luiz; CECCHETTI, Elcio. Do planejamento a prática docente: relato de implantação do Programa Mais Educação em uma cidade do Oeste catarinense

de colocação em ação, é um processo mental, de reflexão, de decisão, por sua vez, não uma reflexão qualquer, mas grávida de intenções na realidade", por isso exige o envolvimento e comprometimento de todos.

Destaca o professor 1, este que é participante do planejamento do Programa, que:

[...] acredito que a maior dificuldade de muitos professores em estabelecer relação com o programa está relacionada com a formação inicial que não apresenta um aporte sobre o que é a Educação Integral, claro, sei que és algo novo, mas que então, deveria se pensar em formação continuada direcionada aos professores da escola com essa temática (Professor 1) iv

O que o professor apresenta é a necessidade de formação e conhecimento sobre as propostas do Programa, quais objetivos se quer alcançar e quais caminhos seguir. Para Zabala (1998, p. 93), o professor precisa conhecer "o objetivo e o maior número de meios e estratégias/caminhos para atender as diferentes demandas que aparecerão no transcurso do processo de ensino/aprendizagem".

Além disso, o professor aponta outra inquietação sobre a necessidade de que unidades de formação inicial proporcionem conhecimento sobre o que é Educação integral, o que ainda, a unidade, escola, pense em um processo de formação continuada a esses professores com o intuito de apresentar a Educação Integral e formas de se trabalhar com ela.

Segundo Moll (2004) o Programa Mais Educação pode ser apresentado como uma possibilidade de proporcionar aos indivíduos uma educação que busca contemplar o seu desenvolvimento pleno considerando o aspecto afetivo, intelectual, moral e social que o constitui o ser como um todo, mas que para isso faz-se importante a troca de conhecimento por parte de quem detém de experiências na escola.

Com isso, adentra-se na questão de planejamento, e ressalta-se o seguinte relato:

[...] não conheço direito o Programa, não participo porque não sei certo como contribuir, acredito que precisaria de mais formação, conhecimento sobre a Educação Integral, é difícil auxiliar na construção de um planejamento que você não tem domínio da temática, assim, evito participar (Professor 2) ${ }^{\vee}$

Para Zanon e Althaus (2010, p. 29) destacam que "o ato de planejar, organizar as ações docentes e discentes, exige o domínio de conhecimentos sobre os níveis que compõem o processo de planejamento" por isso, participar dos momentos de formação e de planejamento coletivo é importante, pois possibilita o acesso ao conhecimento e envolvimento do processo.

\footnotetext{
iv Professor de Geografia
}

v Professor de Artes 
OLIVEIRA, Marineiva Campos de; TEDESCO, Anderson Luiz; CECCHETTTI, Elcio. Do planejamento a prática docente: relato de implantação do Programa Mais Educação em uma cidade do Oeste catarinense

A partir dos relatos dos professores, pode-se apresentar que a formação continuada seria uma possibilidade de efetivação de um planejamento coletivo, pois, com a proposta do Programa sendo conhecidos por todos, facilitaria a interação e as contribuições de professores e monitores.

\section{Considerações finais}

No decorrer do relato, observamos que os professores da escola e os monitores do Programa Mais Educação estão, sim, preocupados em planejar suas aulas, mas apresentam dificuldades e relacionam essas dificuldades na falta de formação continuada na perspectiva de Educação Integral. Além disso, mostrou que a grande maioria ainda não conhece efetivamente a proposta educacional do Programa Mais Educação, por falta de não ocorrer formações relacionadas a temática. Constatação menos positiva foi observar ainda, que por parte da escola falta pensar em proporcionar momentos de coletividade para professores da escola e professores do programa, pois, a interação não deve ocorrer somente na hora do planejamento.

É essencial que os docentes, juntamente com a equipe diretiva, criem condições para que ocorra a formação continuada de caráter coletiva, dialógica, e que esta venha ao encontro das necessidades dos docentes, aqui apresentada, as necessidades são de planejar as práticas relacionando-as com a proposta do Programa Mais Educação.

Neste sentido, a contribuição individual por parte de cada professor, para que ao final as contribuições sejam coletivas, podem auxiliar na construção de planejamento que contribua no processo de ensino-aprendizagem, mas para isso, é necessário um planejamento participativo entre toda a comunidade escolar.

Conclui-se que em se tratando de planejar as práticas, convém frisar a importância de asseverar aos docentes formações continuadas que possibilitem o conhecimento das propostas e que conduzam a reflexão sobre como contribuir e mudar o cenário da educação brasileira.

\section{Referências}

ALMEIDA, Benedita de. Formação continuada de professores e escrita: pontos de ancoragem. In: _. A escrita na formação continuada de professoras alfabetizadoras: práticas de autoria. 2007. $251 \mathrm{f}$. Tese (Doutorado) - Faculdade de Educação, Universidade de São Paulo, São Paulo, 2007.

BAKHTIN, Mikhail. A interação verbal. In: BAKHTIN, Mikhail (Volochinov). Marxismo e filosofia da linguagem. 9. ed. Trad.Michel Lahud. São Paulo: Hucitec Annablume, 2002. 
OLIVEIRA, Marineiva Campos de; TEDESCO, Anderson Luiz; CECCHETTI, Elcio. Do planejamento a prática docente: relato de implantação do Programa Mais Educação em uma cidade do Oeste catarinense

BICUDO, F. A entrevista- testemunho: quando o diálogo é possível. Revista Caros Amigos. Disponível em: <http://observatorio.ultimosegundo.ig.com.br/artigos.asp?cod=333DACOO1. Acesso em 17 de mar. 2006.

BRASIL. Câmara dos Deputados. Portaria interministerial no 17/2007. Câmara dos Deputados. Brasília, 2007.

BRASIL. Ministério da Saúde. Conselho Nacional de Saúde. Resolução n. 466, de 12 de dez̧embro de 2012. Aprova diretrizes e normas regulamentadoras de pesquisas envolvendo seres humanos. Brasília, Diário Oficial da União, 12 dez. 2012.

BRASLAVSKY, Berta. Marcos Referenciais. In: didática. Trad. Vera Masagão Ribeiro. São Paulo: UNESP, 1993.

BRZEZINSKI, Iria. Politicas contemporâneas de formação de professores para os anos iniciais do ensino fundamental. Educ. Soc., Campinas, vol. 29, n. 105, p. 1139-1166, set./dez. 2008. Disponível em <http://www.cedes.unicamp.br> Acesso em 30/05/2013.

DENZIN; N LINCOLN, Y. A disciplina e a prática da pesquisa qualitativa. In: DENSIN, N. ; LINCONLN, Y [et al]. O planejamento da pesquisa qualitativa: teoria e abordagens. 2. Ed. Porto Alegre: Artmed, 2006, p. 15-41.

GIL, Antonio Carlos. Como elaborar projetos de pesquisa. 4. ed. São Paulo: Atlas, 2002.

LIBÂNEO, José Carlos. Didática. São Paulo. Editora Cortez, 1994.

MIZUKAMI, M. G. N. REALI, A . M. M. R.(orgs) Formação de professores, práticas pedagógicas e escola. São Carlos: EdUFSCar, 2002.

MOLL, Jaqueline. Ciclos na escola e tempos na vida. Porto Alegre: Artmed, 2004.

POPKEWITZ, Thomas S. Reforma educacional: uma politica socio- lógica B poder e conhecimento em educação. Trad. Beatriz Afonso Neves. Porto Alegre, Artes Médicas, 1997.

SACRISTÁN, J. Gimeno. Consciência e ação sobre a prática como libertação profissional dos professores. In NÓVOA, António. Profissão professor. Porto Editora, 1995.

STRIEDER, Roque. Diretriz̧es para elaboração de projetos de pesquisa: metodologia do trabalbo científico. Joaçaba: Ed. Unoesc, 2009.

VASCONCELLOS, Celso dos Santos. Planejamento projeto de ensino-aprendizagem e projeto políticopedagógico. São Paulo: Cadernos Pedagógicos do Libertad, 2000.

ZABALA, A. A prática educativa: como ensinar. Porto Alegre: ARTMED, 1998.

ZANON, D.P.; ATHAUS, M.T.M. Didática II. Ponta Grossa: UEPG/NUEAD, 2010. 


\section{Dialogia}

OLIVEIRA, Marineiva Campos de; TEDESCO, Anderson Luiz; CECCHET'TI, Elcio. Do planejamento a prática docente: relato de implantação do Programa Mais Educação em uma cidade do Oeste catarinense

Recebido em: 26 dez. 2019 / Aprovado em: 13 mar. 2020

\section{Cite como (ABNT NBR 6023:2018)}

OLIVEIRA, Marineiva Campos de; TEDESCO, Anderson Luiz; CECCHETTT, Elcio. Do planejamento a prática docente: relato de implantação do Programa Mais Educação em uma cidade do Oeste catarinense. Dialogia, São Paulo, n. 34, p. 309-322, jan./abr. 2020. Disponível em: https://doi.org/10.5585/Dialogia.n34.16298. 